Article

\title{
Assessment of the Anticipated Environmental Footprint of Future Nuclear Energy Systems. Evidence of the Beneficial Effect of Extensive Recycling
}

\author{
Jérôme Serp, Christophe Poinssot and Stéphane Bourg * \\ French Nuclear and Alternative Energies Commission, Nuclear Energy Division, Research Department \\ on Mining and Fuel Recycling Processes, CEA Marcoule, F-30207 Bagnols sur Ceze, France; \\ jerome.serp@cea.fr (J.S.); Christophe.poinssot@cea.fr (Ch.P.) \\ * Correspondence: stephane.bourg@cea.fr; Tel.: +33-4-6679-7702
}

Received: 28 July 2017; Accepted: 16 September 2017; Published: 19 September 2017

\begin{abstract}
In this early 21st century, our societies have to face a tremendous and increasing energy need while mitigating the global climate change and preserving the environment. Addressing this challenge requires an energy transition from the current fossil energy-based system to a carbon-free energy production system, based on a relevant energy mix combining renewables and nuclear energy. However, such an energy transition will only occur if it is accepted by the population. Powerful and reliable tools, such as life cycle assessments (LCA), aiming at assessing the respective merits of the different energy mix for most of the environmental impact indicators are therefore mandatory for supporting a risk-informed decision-process at the societal level. Before studying the deployment of a given energy mix, a prerequisite is to perform LCAs on each of the components of the mix. This paper addresses two potential nuclear energy components: a nuclear fuel cycle based on the Generation III European Pressurized Reactors (EPR) and a nuclear fuel cycle based on the Generation IV Sodium Fast Reactors (SFR). The basis of this study relies on the previous work done on the current French nuclear fuel cycle using the bespoke NELCAS tool specifically developed for studying nuclear fuel cycle environmental impacts. Our study highlights that the EPR already brings a limited improvement to the current fuel cycle thanks to a higher efficiency of the energy transformation and a higher burn-up of the nuclear fuel $(-20 \%$ on most of the chosen indicators) whereas the introduction of the GEN IV fast reactors will bring a significant breakthrough by suppressing the current front-end of the fuel cycle thanks to the use of depleted uranium instead of natural enriched uranium (this leads to a decrease of the impact from $17 \%$ on water consumption and withdrawal and up to $96 \%$ on $\mathrm{SO}_{x}$ emissions). The specific case of the radioactive waste is also studied, showing that only the partitioning and transmutation of the americium in the blanket fuel of the SFR can reduce the footprint of the geological disposal (saving up to a factor of 7 on the total repository volume). Having now at disposition five models (open fuel cycle, current French twice through fuel cycle, EPR twice through fuel cycle, multi-recycling SFR fuel cycle and at a longer term, multi-recycling SFR fuel cycle including americium transmutation), it is possible to model the environmental impact of any fuel cycle combining these technologies. In the next step, these models will be combined with those of other carbon-free energies (wind, solar, biomass ... ) in order to estimate the environmental impact of future energy mixes and also to analyze the impact on the way these scenarios are deployed (transition pathways).
\end{abstract}

Keywords: actinides recycling; life cycle assessment; nuclear energy system; environmental impact 


\section{Introduction}

In this early 21st century, our societies have to address a global energy challenge: meeting our tremendous and increasing energy needs while mitigating the global climate change and preserving the environment. Following the COP21 commitment taken in December 2015 in Paris, facing this challenge requires an energy transition from the current fossil energy based system (by order of importance, oil, coal and gas) to a carbon-free energy production system, based on a relevant mix of renewables and nuclear energy. Beyond the need for developing more efficient technologies, such an energy transition will only occur if it is accepted by the population, and will only be beneficial if it demonstrates that it allows the preservation of the global climate and the overall environment. Powerful and reliable tools aiming at assessing the respective merits of the different energy mix for most of the environmental impact indicators are therefore mandatory for supporting a risk-informed decision-process at the societal level.

In this context, Life Cycle Assessment (LCA) methodology is a key tool, defined by ISO 14040 [1] and ISO 14044 [2]. It takes into account the various industrial processes and plants which are involved all along the industrial cycle, as well as the overall life of all these facilities, from the initial construction up to the final dismantling and management of the ultimate waste. This approach is hence often referred to as a "cradle to grave" approach; it averages the different impacts on the whole life of the facilities without any specific consideration at that time for the respective contribution of the different lifecycle stages. We recently published a comprehensive assessment of the French nuclear energy environmental footprint based on a specific LCA tool (Nuclear Energy Life Cycle Assessment Simulation, NELCAS) [3]. In that paper, the results were compared with published data on nuclear energy as well as other energy sources (coal, oil/gas and renewables) showing the consistency and relevance of the methodology developed in the NELCAS tool [3]. Since then, very few papers compared different nuclear fuel cycles; one can mention the study of Kadiyala et al. [4] which focused on the GHG emissions only. In our study, France was selected due to the existence of a very large set of published environmental data in the annual environmental and safety reports produced by any nuclear facility in France thanks to the Nuclear Safety and Transparency Law of 2006. France is also of specific interest as the French nuclear industry covers the whole fuel cycle, from ore mining to geological disposal, through the conversion, the enrichment, the fuel fabrication, the electricity production in the reactors, the fuel storage, the fuel recycling and the different types of waste conditioning plants and interim storage facilities, even though all the steps are not located in France. The ultimate repository planned to be built in France by 2025 is also included. In this work, we demonstrated that spent nuclear fuel (SNF) recycling has a very beneficial environmental impact due to its low impact by comparison to front-end activities, in particular the ore-mining. We demonstrated that implementing SNF recycling leads to decreasing most of the environmental indicators by 10 to $20 \%$ [3]. However, this paper was restricted to the sole comparison of the so-called "Once-Through Cycle" (OTC) in which SNF is considered as an ultimate waste to be disposed of (as it is currently deployed in Finland and Sweden), and the "Twice-Through Cycle" (TTC) in which SNF is treated once to recycle Pu in MOX fuels and U in URE fuels (as it is currently deployed in France). Actually, future nuclear systems are anticipated to progressively evolve as follows:

(i) First by deploying 3rd generation reactors which are derived from the current BWR and PWR in-operation but are reinforced in terms of safety (no radionuclide release in case of core fusion) and efficiency;

(ii) Second by deploying 4 th generation reactors which are aimed to more efficiently consume natural uranium by favoring the transformation of the fertile ${ }^{238} \mathrm{U}$ into fissile ${ }^{239} \mathrm{Pu}$ thanks to higher energy neutrons. They are hence referred to as Fast Neutron Reactors (FNR). In this work FNR taken as reference are Sodium-cooled Fast Reactors for which numerous environmental data are available in France thanks to PHENIX and SUPERPHENIX exploitation. This choice does not reflect the diversity of 4 th generation reactors and their associated fuel cycle explored 
worldwide [5] or in the Generation IV International Forum (GIF) [6] but rather illustrates the benefits of FNR in the French nuclear strategy. Although our paper is based on the French strategy and does not aim at reflecting all the potential future reactors systems, it is important to recall that EPRs can be potentially used also for other innovative fuel cycles [7-9].

Estimating reliable environmental indicators for future nuclear energy systems is therefore an important issue to enlighten the potential benefice and detriment of shifting towards new generations of nuclear energy systems.

In order to assess the potential influence of such new nuclear energy systems, we used the previous NELCAS LCA approach to compare these two scenarios with the current nuclear fuel cycle. We based our estimation on: (i) the known available technologies, respectively the well-known AREVA's European Pressurized Reactor (EPR) for the 3rd generation; and (ii) for the 4th generation, on a theoretical sodium-cooled fast spectrum reactor (SFR) derived from the French ASTRID project and the feedback of the former PHENIX and SUPERPHENIX reactors. Based on the French R\&D strategy, we also studied the impact of the various kinds of nuclear fuel cycles that could be implemented with FNR, i.e., the Pu-multi-recycling (the so-called Multi-Through Cycle, MTC) and the additional Am-sole recycling for transmutation. Indeed, in the frame of the French Act of 28 June 2006 on the sustainable management of radioactive materials and wastes, CEA was committed to develop new processes and technologies suitable for reducing the ultimate waste long-term toxicity thanks to an efficient partitioning and transmutation (P\&T) of the long-lived radionuclides.

\section{Presentation of the Various Scenarios under Study}

Performing relevant LCA calculations for nuclear energy requires considering the overall nuclear fuel cycles which includes the following steps:

- The fuel cycle front-end including the ore-mining and milling, the conversion of $\mathrm{U}_{3} \mathrm{O}_{8}$ into $\mathrm{UF}_{6}$, the enrichment of $\mathrm{UF}_{6}$, the conversion of $\mathrm{UF}_{6}$ to oxide, and the fuel manufacturing;

- The electricity production in the considered reactors fleet;

- The fuel cycle back-end including the discharging of SNF from the reactor, its decay storage before reprocessing it to recycle $\mathrm{Pu}$ in MOX fuel, $\mathrm{U}$ in URE and potentially Am for transmutation. It also includes the conditioning and the disposal of the ultimate waste (High-Level and Long-Lived Medium-Level Waste) in a deep geological repository.

The current French fuel cycle (TTC) as described in a previous paper [3] is the reference fuel cycle. Theoretical future French fleets were derived from the current situation by: (i) replacing the current reactors with 3rd and then 4th generation reactors in order to produce the same amount of electricity; and (ii) adapting the overall material and energy fluxes in the various steps of the nuclear fuel cycle. Following sections describe the different stages which have been studied.

\subsection{Case Study of a $100 \%$ EPR Fleet}

The first theoretical case corresponds to the replacement of current 2nd generation reactors by 3 rd generation reactors, namely EPR. The corresponding fuel cycle with the reference annual fluxes are presented in Figure 1. In this case study, the current 58 PWRs ( 34 of 900 MWe, 20 of 1350 MWe and four of $1450 \mathrm{MWe}$ ) are replaced by 38 EPR in order to produce 453 TWhe per year. The EPR reactor considered for our calculation has the following characteristics:

- $\quad$ an electrical production capacity of 1600 MWe;

- a thermal efficiency of $36 \%$ with an availability of $85 \%$;

- a fuel burn-up of $55 \mathrm{GWd} / \mathrm{tU}$ to be compared to the current average burnup of $40 \mathrm{GWd} / \mathrm{tU}$;

- a reactor lifetime of 60 years (conception lifetime). 


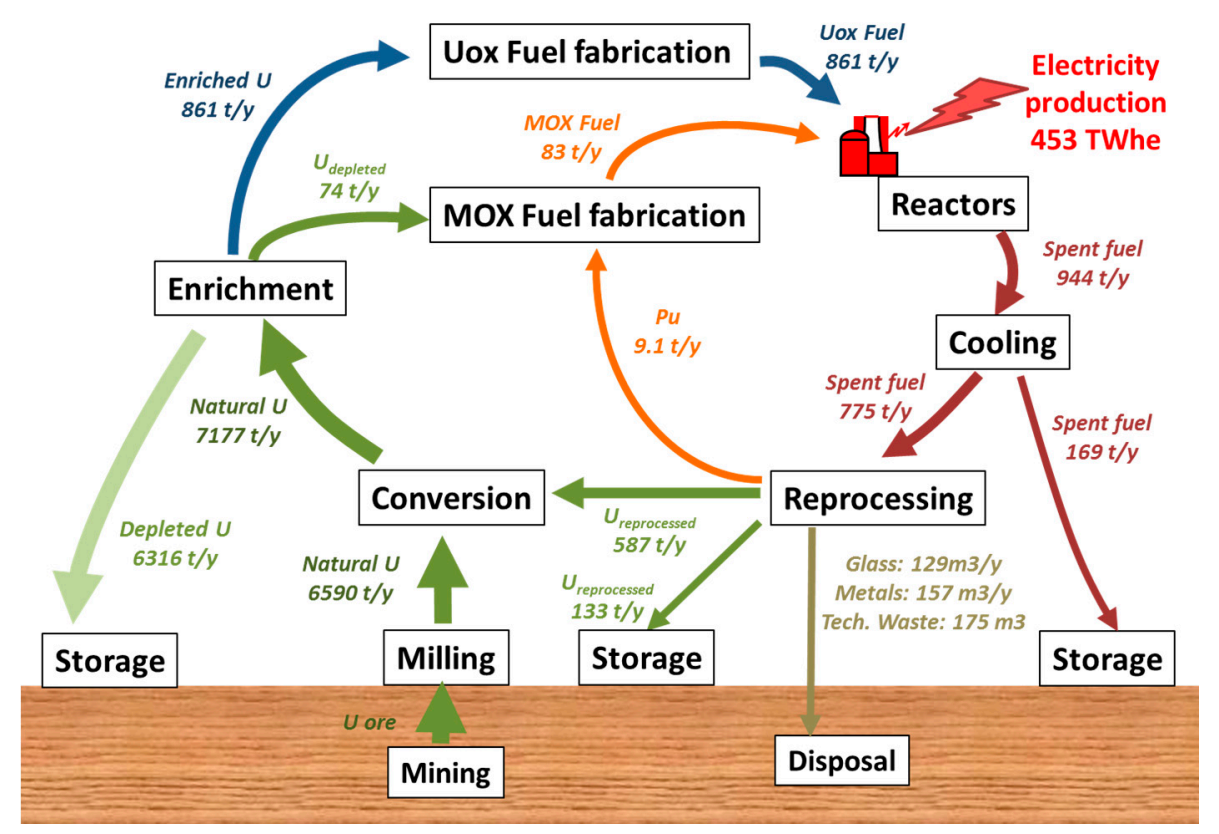

Figure 1. Nuclear fuel cycle for the $100 \%$ EPR case study and its representative streams.

In order to equilibrate the nuclear material fluxes and balance, among the 38 EPR fleet:

- 24 are only fed with UOX fuel manufactured from enriched U-ore;

- 11 use both UOX and MOX fuel with a ratio of $30 \%$ of MOX in the reactor core, and a plutonium content of $10.9 \%$ in the MOX fuel;

- three use reprocessed uranium fuel (URE). For this purpose $587 \mathrm{t}$ of reprocessed $\mathrm{U}$ have to be re-enriched up to $4.5 \%{ }^{235} \mathrm{U}$ content.

Therefore, the corresponding nuclear fuel requires $861 \mathrm{t}$ of UOX and $83 \mathrm{t}$ of MOX to be yearly charged in the reactors and discharged four years later. In this case study, we assume that the reprocessing plant only treats UOX fuel, the MOX fuel being temporarily stored to be used in the future FNR. Up to 2012, the French enrichment plant used gaseous diffusion (Georges Besse I plant, GB I) which required much more energy $(2400 \mathrm{kWh} / \mathrm{SWU})$ than the most recent ultracentrifugation (100 kWh/SWU) which has been used since 2012 (Georges Besse II plant, GB II). In this study, the former enrichment by gaseous diffusion was considered in the TTC case whereas the ultracentrifugation process is taken in consideration for the EPR fleet.

\subsection{Theoretical Case Study of a $100 \%$ SFR Fleet}

This case study considers the very hypothetical far-future case where the French fleet could only be composed of FNR, typically SFR. We recognize that such a situation is not realistic but it was however used to better evidence the respective influence of FNR on the environmental footprint. Obviously, all the linear combination of both 3rd (GEN III) and 4th (GEN IV) generation reactors (respectively EPR and SFR) could be simultaneously operated, and our models allow calculating all these different situations.

In a theoretical pure GEN IV FNR fuel cycle, a stable plutonium mass balance is achieved thanks to the multi-recycling of plutonium in MOX fuel and the intrinsic characteristics of FNR which allows the transformation of fertile ${ }^{238} \mathrm{U}$ in fissile ${ }^{239} \mathrm{Pu}$ : the mass of plutonium which is yearly introduced as fuel in the reactor is identical to those at the outlet of the reprocessing plant. In such a nuclear fuel cycle, the front-end operations are not needed anymore and disappeared. FNR MOX fuel is therefore manufactured from recycled $\mathrm{Pu}$ and from either reprocessed or depleted uranium, this latter being quite abundant in France due to the operation of the 2nd and 3rd generation reactors (the total 
stockpile is estimated to be around 410,000 $\mathrm{t}$ end of 2030 according to ANDRA [10]. Moving to GEN IV reactors would then highly reduce the need natural uranium and therefore increase the self-sufficiency in uranium of countries in high nuclear energy development such as China [11]. The representative fluxes are shown in Figure 2.

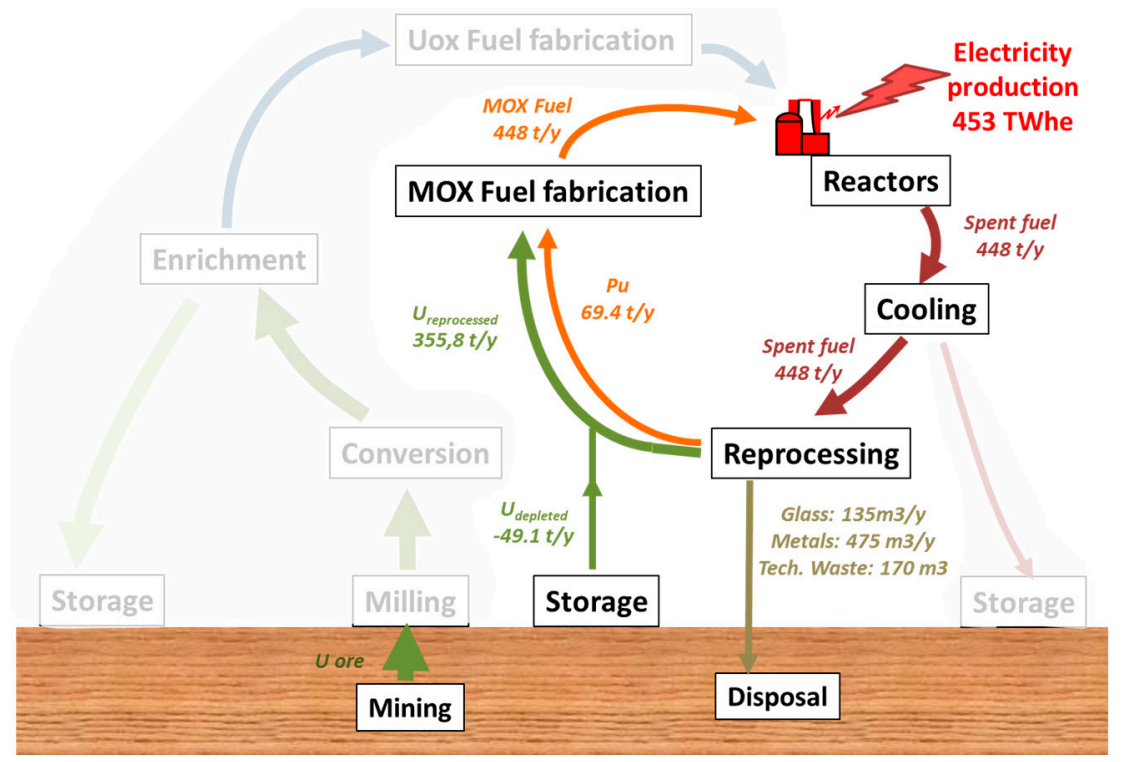

Figure 2. Nuclear fuel cycle for the $100 \%$ SFR case study and its representative streams.

The SFR reactor considered for our calculation has the following characteristics:

- an electrical production capacity of $1450 \mathrm{MWe}$

- achieves $40 \%$ thermal efficiency with an availability of $85 \%$,

- MOX containing $15.5 \%$ of plutonium is used to feed the reactor and the average fuel burn-up is increased to $100 \mathrm{GWd} / \mathrm{tU}$,

- The lifetime of the reactor is anticipated to be 60 years (conception lifetime).

For producing a similar electrical output of 453 TWhe/y, the modelled fleet is composed of 42 SFR which have to be fed with $448 \mathrm{t}$ of MOX fuel, requiring the annual use of $\sim 50 \mathrm{t}$ of reprocessed or depleted uranium from the French stockpile.

\section{Presentation of the LCA Methodology and the NELCAS Tool}

\subsection{Selection of Key Environmental Indicators}

The methodology and the selection of the environmental indicators employed is this work has already been comprehensively described previously [3]. The eight key generic indicators as well as the five additional potential indicators are displayed on Figure 3. The impact are normalized to the amount of electricity produced in each considered scenario (e.g., for GHG emissions, GWP 100-gCO ${ }_{2} \mathrm{eq} / \mathrm{kWhe}$ ). In order to tackle impacts specific to the nuclear industry, radioactive gaseous and liquid emissions and solid wastes are also reported in this paper. 


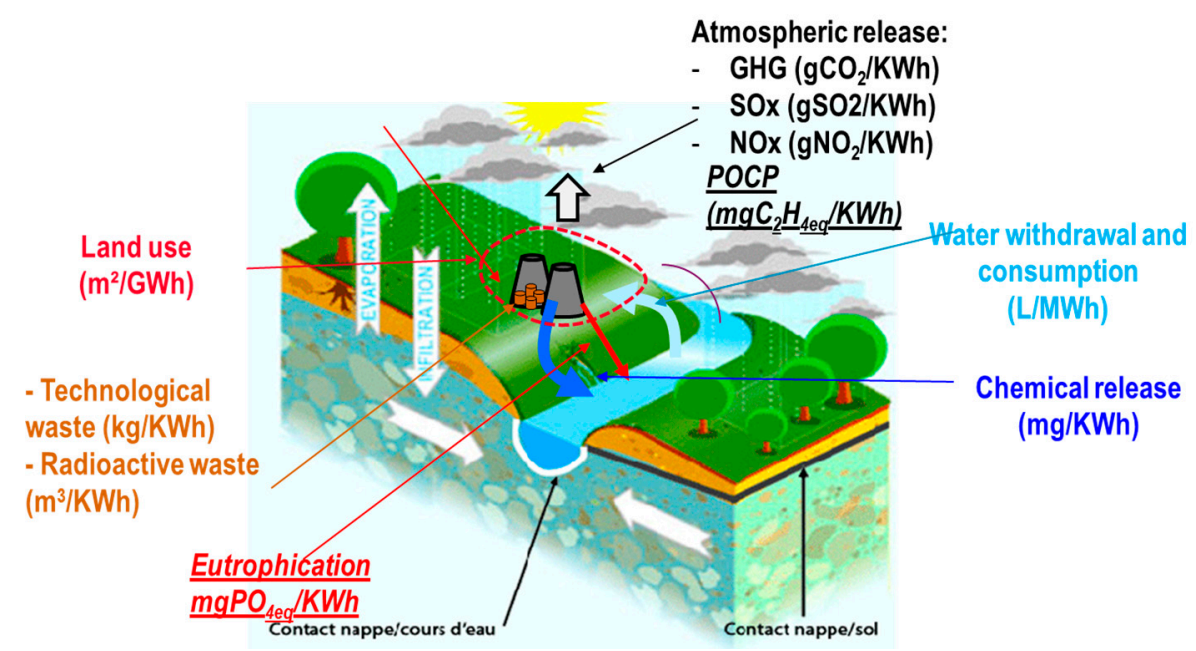

Figure 3. Synthesis of the various environmental indicators studied in this study.

\subsection{Presentation of the NELCAS LCA Tool}

In order to assess key environmental indicators, we used the simulation tool NELCAS [3] that has been developed for easily assessing environmental indicators based on published data. This tool has been specifically focused on the French nuclear energy system. It also allows the calculation of future scenario with Gen III and IV reactors and their comparison with the current nuclear French situation. NELCAS is supported by data issued from CEA's reference calculation tools:

- Simplified Evolution Code Applied to Reprocessing (CESAR) is an evolution code developed in partnership CEA/AREVA-NC which allows a rapid assessment of the isotopic evolution of 109 actinides, 209 fission products and 146 activation products within SNF, and provides concentration values, residual power, activities, and sources of penetrating radiation [12].

- COSI [13] like NELCAS simulates a fleet of nuclear power plants with their associated fuel cycle facilities (enrichment, reprocessing ... ). The major goal of this code is take into consideration, for various future scenarios with Gen III and Gen IV reactors deployment, the overall balance of nuclear materials. This includes in function of time precise nuclear materials fluxes between facilities, nuclear fuel burn-up, spent nuclear fuel cooling time and reprocessing timeline, isotopic composition constraints ...

All the data used in the calculations were taken from the available public data or come from internal CEA conceptual design study reports for the most advanced fuel cycle options. In particular, the yearly environmental reports of each of the French nuclear facility were intensively used to get data about the annual energy and chemicals consumption as well as the production of any type of waste. Information, references and specific assumptions are given in Table 1. 
Table 1. The different steps of the fuel cycle with assumptions made and references used for building the LCA NELCAS database.

\begin{tabular}{|c|c|c|c|}
\hline Fuel Cycle Step & Site & Operation & Ref. \\
\hline \multirow{4}{*}{ Front-end of the fuel cycle } & $\begin{array}{l}\text { Mines (Areva Production): } \\
\text { - Canada ( } 26 \% \text {, underground) } \\
\text { - Niger }(33 \% \text {, open-pit) } \\
\text { - Kazakhstan }(41 \%, \text { ISL) }\end{array}$ & $\begin{array}{l}\text { Origin of data identical to those already reported for the current French nuclear cycle and } \\
\text { adjusted to the calculated for the EPR scenario }\end{array}$ & [3] \\
\hline & Malvési (Narbonne) & $\begin{array}{l}\text { Origin of data identical to those already reported for the current French nuclear cycle and } \\
\text { adjusted to the calculated for the EPR scenario }\end{array}$ & [3] \\
\hline & Tricastin (Pierrelatte) & $\begin{array}{l}\text { Origin of data identical to those already reported for the current French nuclear cycle and } \\
\text { adjusted to the calculated nuclear material fluxes for the EPR scenario }\end{array}$ & [3] \\
\hline & Romans & $\begin{array}{l}\text { Origin of data identical to those already reported for the current French nuclear cycle and } \\
\text { adjusted to the calculated for the EPR scenario }\end{array}$ & [3] \\
\hline \multirow{2}{*}{ Energy production } & 38 EPR (1600 MWe) fleet & $\begin{array}{l}\text { EPR:: Data provided by EDF (report "Flamanville } 3 \text { head EPR series-Client Folder" EPR } \\
\text { UK reports, Part of civil engineering data provided by the Quille company, ECOINVENT } \\
\text { data extrapolated from current LWR + CEA expertise for fuel management. }\end{array}$ & [14-17] \\
\hline & 42 SFR (1450 MWe) fleet & $\begin{array}{l}\text { SFR: Data provided by EDF and CEA, taking into account both Phenix and Superphenix } \\
\text { reactors experience feedback. Data extrapolated from CEA-Phenix reports concerning the } \\
\text { authorization of discharges and water withdrawals, data from CEA system studies for } \\
\text { technological waste and fuel management. }\end{array}$ & {$[18,19]$} \\
\hline \multirow{4}{*}{ Back-end of the fuel cycle } & La Hague & Data from CEA system studies, Data from AREVA TSN reports of La Hague plant & {$[3,20-22]$} \\
\hline & Tricastin (Pierrelatte) & Data from CEA studies or scenarios and AREVA TSN reports & {$[3,20-23]$} \\
\hline & MELOX plant (Marcoule) & Data from CEA studies or scenarios and AREVA TSN reports & {$[23,24]$} \\
\hline & $\begin{array}{l}\text { Storage/Disposal: } \\
\text { Aube (VLLW, ILW-SL) Meuse-Haute Marne (CIGEO project for } \\
\text { an underground long term disposal site for ILW-LL and HLW) }\end{array}$ & Data from CEA scenario or studies and ANDRA associated reports. & {$[22,25]$} \\
\hline Transports & Between every sites described above & Origin of data identical to those already reported for the current French nuclear cycle & [3] \\
\hline Construction, dismantling & & Data derived from EcoInvent, CEA system studies, and ANDRA & {$[3,26]$} \\
\hline
\end{tabular}




\section{Presentation of the Environmental Indicators for Potential Future Nuclear Energy Systems}

\subsection{The $100 \%$ EPR Case Study}

Table 2 presents the results for the different environmental and technological indicators as well as radioactive releases and wastes for both the current French TTC [3] and the 100\% EPR fleet case study. These data indicate that an EPR reactor fleet would achieve a reduced environmental footprint (roughly $-20 \%$ for most of the selected indicators) versus the current PWR French fleet. These improvements at equal amount of electricity produced are mainly attributed to the improved reactor characteristics:

- An increase steam pressure ( $>77$ bar) which allows a higher turbine efficiency, up to $37 \%$. This value is currently lower for PWR: 32-33\% for 900 MWe (34 reactors in France) and 34-35\% for 1300 MWe and 1450 MWe (20 reactors);

- The EPR is expected to achieve a higher availability rate of $85 \%$ compared to the current PWR fleet due to the possibility of realizing some maintenance operations during reactor operation (74\% observed in 2010);

- A design lifetime of 60 years, versus 40 years for the current PWR reactors, must also be taken into consideration since the calculated impacts are averaged on the whole lifetime of a plant.

Table 2. NELCAS results for the environmental and technological impact indicators for the French TTC [3] compared with a 100\% EPR fleet (this study).

\begin{tabular}{|c|c|c|c|c|}
\hline Impact Indicators & Unit & TTC & EPR & Difference $\%$ \\
\hline GHG emissions & $\mathrm{gCO}_{2} \mathrm{eq} / \mathrm{kWhe}$ & 5.29 & 3.97 & $-24 \%$ \\
\hline Atmospheric pollution $\mathrm{SO}_{\mathrm{x}}$ & $\mathrm{g} /$ MWhe & 16.3 & 12.7 & $-22 \%$ \\
\hline Atmospheric pollution $\mathrm{NO}_{\mathrm{x}}$ & g/MWhe & 25.3 & 21.35 & $-20 \%$ \\
\hline Land-use & $\mathrm{m}^{2} / \mathrm{GWhe}$ & 211.0 & 161.6 & $-23 \%$ \\
\hline Natural ressource efficiency & kU/TWhe & 18.7 & 15.2 & $-19 \%$ \\
\hline Water consumption & L/MWhe & 1507 & 1437 & $-5 \%$ \\
\hline Water withdrawal & L/MWhe & 72,364 & 70,132 & $-3 \%$ \\
\hline Acidification potential & $\mathrm{gSO}_{2} \mathrm{eq} / \mathrm{MWhe}$ & 35.1 & 27.7 & $-21 \%$ \\
\hline POCP & $\mathrm{gC}_{2} \mathrm{H}_{4} \mathrm{eq} / \mathrm{MWhe}$ & 2.88 & 2.27 & $-21 \%$ \\
\hline Ecotoxicity & g1,4-DCB eq/MWhe & 638.2 & 499.6 & $-22 \%$ \\
\hline Human toxicity & g1,4-DCB eq/MWhe & 1235.1 & 967.1 & $-22 \%$ \\
\hline Eutrophication & $\mathrm{gPO}_{4} \mathrm{eq} / \mathrm{MWhe}$ & 5.45 & 4.18 & $-23 \%$ \\
\hline Liquid chemical effluents & $\mathrm{kg} / \mathrm{GWhe}$ & 287.53 & 225.40 & $-22 \%$ \\
\hline Technological wastes & $\mathrm{kg} / \mathrm{GWhe}$ & 26.38 & 20.42 & $-23 \%$ \\
\hline Gaseous radioactive releases & $\mathrm{MBq} / \mathrm{kWhe}$ & 1.22 & 1.14 & $-7 \%$ \\
\hline Liquid radioactive releases & $\mathrm{kBq} / \mathrm{kWhe}$ & 27.2 & 33.5 & $23 \%$ \\
\hline Total radioactive releases & $\mathrm{MBq} / \mathrm{kWhe}$ & 1.25 & 1.17 & $-6 \%$ \\
\hline VLLW & $\mathrm{m}^{3} /$ TWhe & 3217.6 & 2610 & $-19 \%$ \\
\hline ILW-SL & $\mathrm{m}^{3} /$ TWhe & 30.21 & 19.4 & $-36 \%$ \\
\hline ILW-LL & $\mathrm{m}^{3} /$ TWhe & 1.18 & 0.767 & $-35 \%$ \\
\hline HLW & $\mathrm{m}^{3} /$ TWhe & 0.36 & 0.298 & $-16 \%$ \\
\hline
\end{tabular}

Figure 4 shows the relative contribution of each step of the fuel cycle to the various environmental indicators calculated with NELCAS for the 100\% EPR case study. On this figure the nuclear wastes generated by the complete cycle are also reported. As for current French TTC, mining and reactors are the main contributors to most of the environmental indicators. Hence, $\mathrm{SO}_{2}$ and $\mathrm{NO}_{\mathrm{x}}$ emissions, water pollution and land use indicators are driven by the mining operations whereas water consumption and withdrawal and technological waste indicators are driven by the reactor operation. However, GHG emissions mainly come from mining, reactors operation and enrichment. Very-low-level waste (VLLW) mainly come from mining operations, low and intermediate level short-lived or long-lived waste (LILW-SL and LILW-LL) are balanced between reactor and spent nuclear fuel (SNF) reprocessing activities, whereas high-level waste (HLW) are mainly incorporated in 
glass at the reprocessing plant. Our results are somehow of the same order of magnitude than the one published in 2007 by the NEEDS project [27].

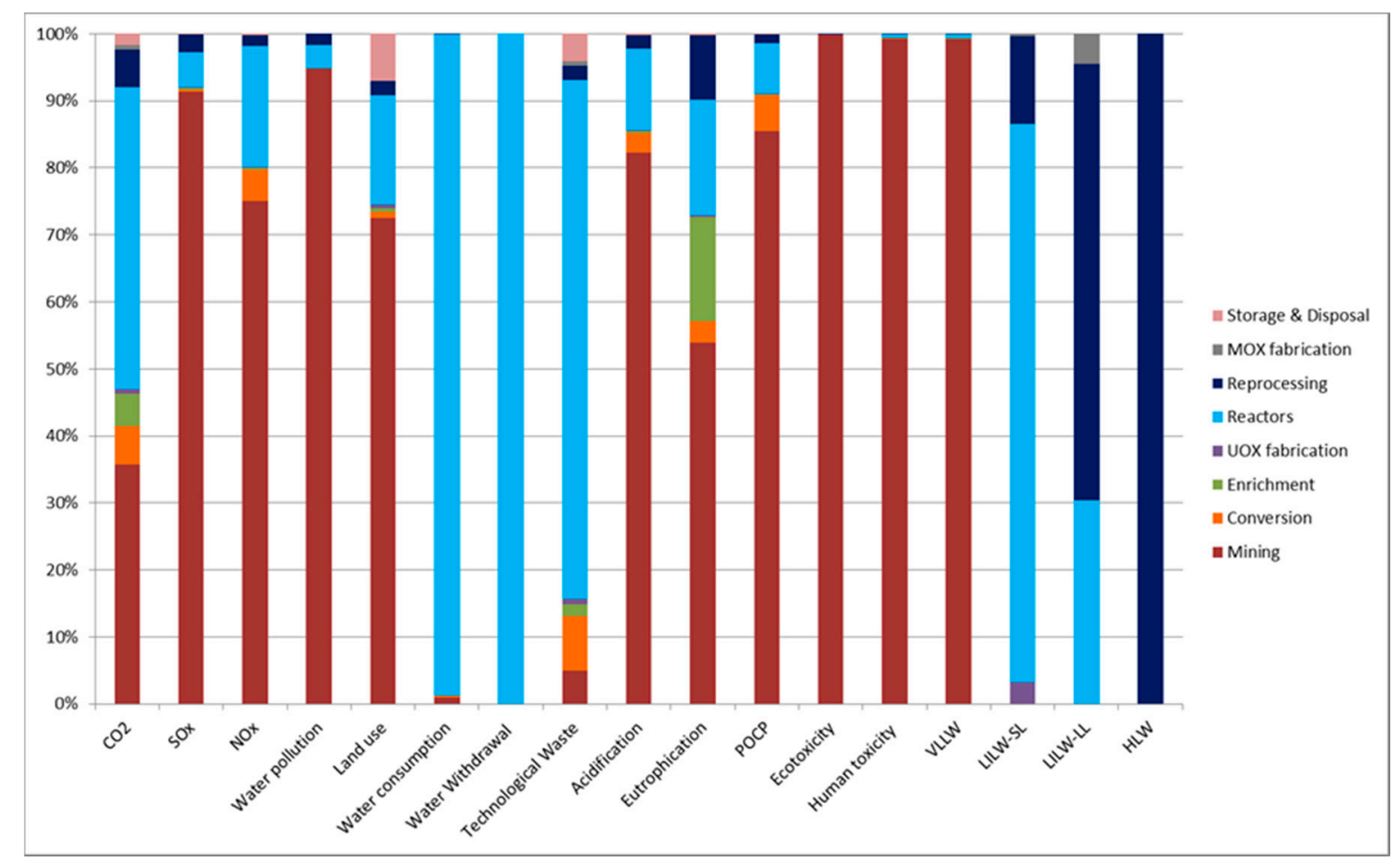

Figure 4. Relative contribution of each step of the fuel cycle to the environmental and technological impact indicators for the French EPR case study.

In this study (see Natural resource efficiency in Table 2), the EPR performances allow saving $19 \%$ of fuel per kWhe (861 t/y for EPR vs. $1053 \mathrm{t} / \mathrm{y}$ for current PWR) in good agreement with the $17 \%$ value published by EDF on the basis of a comparison with 1300 MWe reactors [28]. This higher efficiency obviously improves the numerous indicators which are mainly governed by the front-end operations, such as $\mathrm{SO}_{x}, \mathrm{NO}_{x}$, water pollution, land-use, acidification, eutrophication, $\mathrm{POCP}$, ecotoxicity and human toxicity (Figure 5). The higher efficiency also leads to a lower flux in the back-end of the fuel cycle and to a decrease of the waste volumes whatever the category considered (Figure 5).

The only indicators which are degraded are the tritium releases and the other radionuclides liquid releases. Globally, the total radioactive releases of the EPR scenario (1.14 MBq/kWhe) are only decreased by $6 \%$ compared to the TTC (see Table 2 ) in relative agreement with the reduced nuclear fuel needs $(-19 \%)$. The gaseous emissions which account for more than $97 \%$ of the total releases are reduced by $7 \%$ whereas the liquid releases are increased by $23 \%(33.5 \mathrm{kBq} / \mathrm{kWhe})$. To understand this last value, the assumption used for the calculations as well as the main contributors to gaseous and liquid radioactive releases (Figures 6 and 7) must be considered.

The main contribution to gaseous radioactive releases are rare gas emissions coming from the spent fuel dissolution in the reprocessing plant $(63.3 \%)$ and radon emitted during mining operations (36.5\%). The yearly rare gas emissions in the reprocessing plant (mainly $85 \mathrm{Kr}$ ) in the EPR scenario was assessed by taking into account the fuel composition after irradiation $(55 \mathrm{GWd} / \mathrm{t})$ and five years cooling time using the CESAR code, assuming that $100 \%$ of those gases are released during the spent fuel dissolution step. 


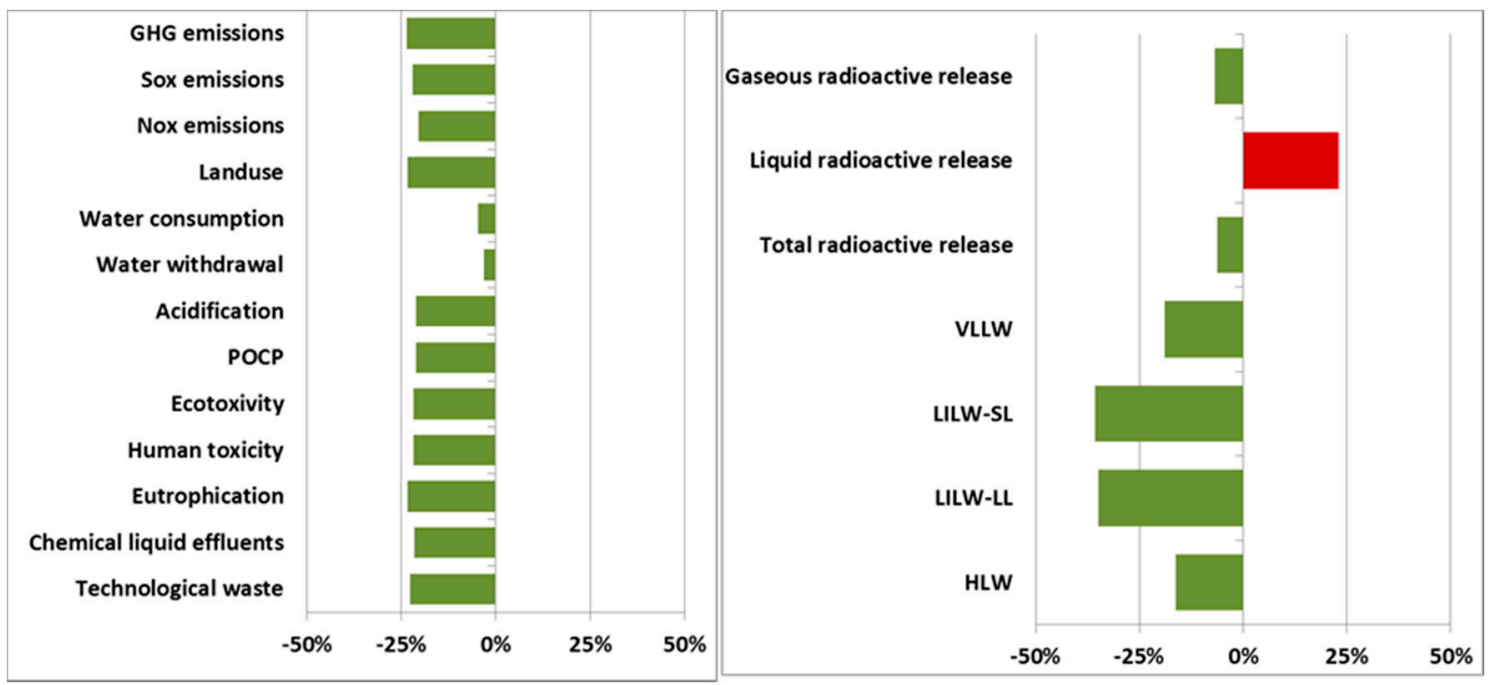

Figure 5. Comparison of the environmental indicators for the $100 \%$ EPR case study relative to the current French TTC [3].

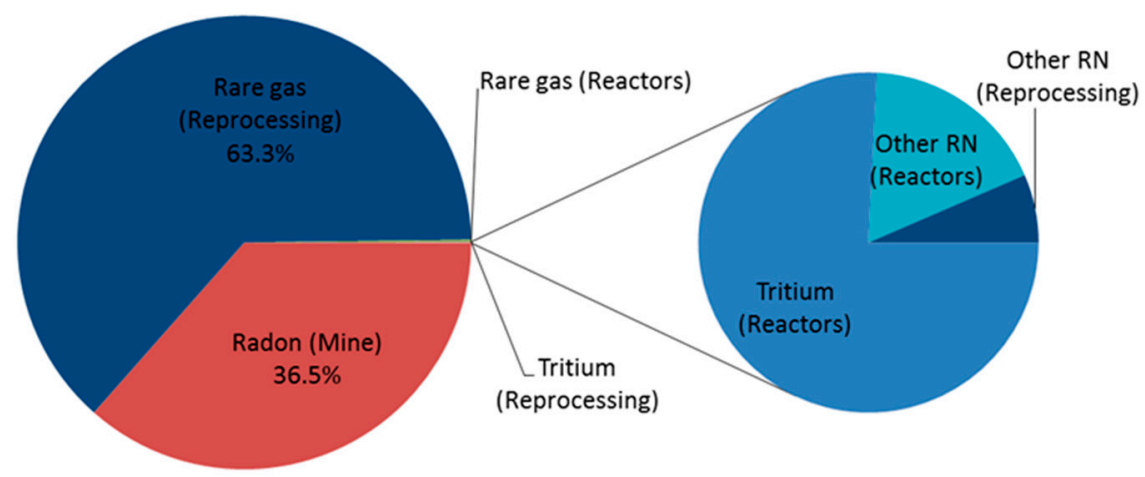

Figure 6. Main contributions associated to gaseous releases (1.14 MBq/kWhe) for the $100 \% \mathrm{EPR}$ case study.

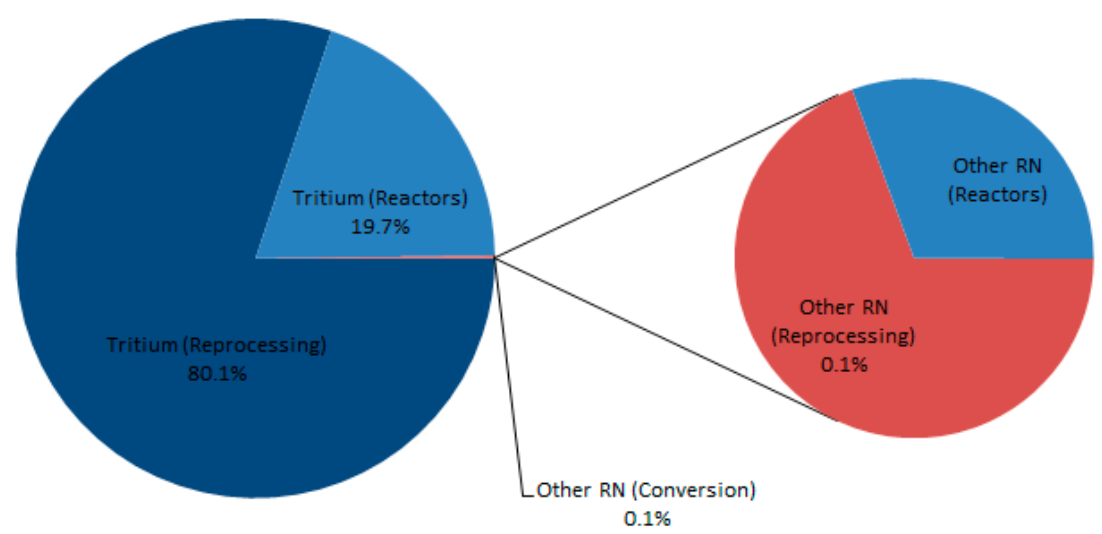

Figure 7. Main contributions associated to liquid releases ( $33.5 \mathrm{kBq} / \mathrm{kWhe}$ ) for the $100 \%$ EPR case study.

For the liquid radioactive releases, the main contributors are the tritium coming from the reprocessing step $(80.1 \%)$ and from reactors $(19.7 \%)$. The first value was obtained by using the CESAR code (five years cooling) and assuming that $65 \%$ of the tritium generated during the irradiation time $(55 \mathrm{GWd} / \mathrm{t}$ ), according to CEA expertise, is transferred to nitric acid during the spent fuel dissolution step. The tritium contribution to liquid radioactive releases for EPR taken for this study (75 TBq) is 
the maximum annual radioactive discharges given by EDF [14] for a single EPR. The maximum value given by AREVA-EDF [29] for the UK EPR project at Hinkley Point is in a similar range (52-75 TBq/y) but this report mentions that these limits need to be further investigated. The conservative value retained in this study, $75 \mathrm{TBq}$ for a single EPR (1600 MW), is thus overestimated when compared for example with the current PWR yearly tritium discharge: $60 \mathrm{TBq}$ [30] for two $1300 \mathrm{MW}$ PWR (Flamanville $1 \& 2$ site where the EPR is under construction). Changing in the NELCAS tool the EPR tritium liquid release from $75 \mathrm{TBq}$ to $52 \mathrm{TBq}$ leads to a $16 \%$ increase of the radioactive liquid emissions instead of $23 \%$ when switching from the current TTC to the EPR scenario (see Table 2). Moreover, both tritium and $85 \mathrm{Kr}$ which dominate liquid and gaseous radioactive releases are short half-life radionuclides (12.32 and 10.76 years respectively) which means that the spent nuclear fuel cooling time influences these releases. By assuming a five years cooling time for the SNF, the radioactive liquid release is increased by $23 \%$ between TTC and EPR scenario (see Table 2). With a seven years cooling time, this increase is cut down to $8 \%$ and to $1 \%$ by combining both a longer cooling time (7 years) and a more reasonable value for the EPR liquid tritium release (52 TBq instead of $75 \mathrm{TBq}$ ). This quick sensitivity analysis is a typical case for which we have chosen to develop a home-made tool in which we can master data representative to the French nuclear cycle. It further underlines the difficulty in comparing the reported radioactive releases of the current fleet with future scenarios.

\subsection{Environmental Indicators for a $100 \%$ SFR Case Study}

Environmental indicators for the $100 \%$ SFR case study and the comparison with the environmental footprint of current French TTC are given in Table 3, Figures 8 and 9.

By comparison to the current fuel cycle, these results demonstrate that a FNR fleet allows a significant improvement of the overall environmental footprint: for instance, greenhouse gas emissions are cut down to $2.33 \mathrm{~g} / \mathrm{kWhe}(-55 \%), \mathrm{SO}_{2}$ and $\mathrm{NO}_{\mathrm{x}}$ emissions as well as land use which are predominantly driven by mining operations are drastically lowered ( $-96 \%$ and $-86 \%$ respectively). A less marked reduction is observed for water withdrawal and water consumption $(-17 \%)$ and technological wastes $(-29 \%)$ since these impact indicators are governed by reactors. The additional potential impact indicators driven by $\mathrm{SO}_{2}, \mathrm{NO}_{x}$ and water pollution mainly associated to the mining operation (see Figure 4 ) are thus also decreased: acidification potential $(-91 \%)$, eutrophication $(-67 \%)$, POCP $(-94 \%)$, human toxicity and ecotoxicity (almost $-100 \%)$. These significant decreases are due to two main reasons:

- The SFR reactors can completely be fed by recycled $U$ and Pu and a limited amount of depleted uranium (less than $50 \mathrm{t} / \mathrm{y}$ from the huge French stockpile, higher than 400,000 t) and theoretically, no additional uranium ore is needed. This allows us to skip (for a very long period of time) the use of uranium mines which have a predominant role for many impact indicators as previously shown on Figure 4. In the absence of any front-end activities, the impacts become dominated by reactors operation and SNF reprocessing as shown on Figure 8.

- The SFR reactors have a higher thermal efficiency (in the range of $40 \%$ to be compared to $33 \%$ for the classical LWR). Therefore, it also allows decreasing the indicators which are dominated by the reactors operation, such as water withdrawal and consumption.

These results illustrate the strong potential of Generation IV nuclear energy systems to provide sustainable energy generation that not only meet low GHG emissions but also efficiently use natural resource and preserve the environment. Our results are somehow of the same order of magnitude than the one published in 2007 by the NEEDS project but for the GHG that looks quite low in the NEEDS report $\left(<1 \mathrm{gCO}_{2} \mathrm{eq} / \mathrm{kWhe}\right)[27]$. 
Table 3. NELCAS results for the environmental indicators for the $100 \%$ SFR case study compared to the reference current French TTC [3].

\begin{tabular}{|c|c|c|c|}
\hline Impact Indicators & Unit & SFR Scenario & Difference vs. TTC \\
\hline GHG emissions & $\mathrm{gCO}_{2} \mathrm{eq} / \mathrm{kWhe}$ & 2.33 & $-55.3 \%$ \\
\hline $\mathrm{SO}_{\mathrm{x}}$ emissions & g/MWhe & 0.59 & $-96.3 \%$ \\
\hline $\mathrm{NO}_{\mathrm{x}}$ emissions & g/MWhe & 3.83 & $-85.7 \%$ \\
\hline Land-use & $\mathrm{m}^{2} / \mathrm{GWhe}$ & 50.2 & $-76.2 \%$ \\
\hline Water consumption & L/MWhe & 1237 & $-17.9 \%$ \\
\hline Water withdrawal & L/MWhe & 60,336 & $-16.6 \%$ \\
\hline Acidification & $\mathrm{gSO}_{2} \mathrm{eq} / \mathrm{MWhe}$ & 3.3 & $-90.7 \%$ \\
\hline POCP & $\mathrm{gC}_{2} \mathrm{H}_{4}$ eq/MWhe & 0.18 & $-93.8 \%$ \\
\hline Ecotoxicity & g1,4-DCB eq/MWhe & 0.07 & $-100.0 \%$ \\
\hline Human toxicity & g1,4-DCB eq/MWhe & 4.8 & $-99.6 \%$ \\
\hline Eutrophication & $\mathrm{gPO}_{4}$ eq/MWhe & 1.8 & $-67.1 \%$ \\
\hline Liquid chemical effluents & $\mathrm{kg} / \mathrm{GWhe}$ & 12.6 & $-95.6 \%$ \\
\hline Technological waste & $\mathrm{kg} / \mathrm{GWhe}$ & 18.70 & $-29.1 \%$ \\
\hline Gaseous radioactive release & $\mathrm{kBq} / \mathrm{kWhe}$ & 528 & $-56.8 \%$ \\
\hline Liquid radioactive release & $\mathrm{Bq} / \mathrm{kWhe}$ & 3557 & $-86.9 \%$ \\
\hline VLLW & $\mathrm{m}^{3} /$ TWhe & 72.4 & $-97.8 \%$ \\
\hline LILW-SL & $\mathrm{m}^{3} /$ TWhe & 18.2 & $-39.7 \%$ \\
\hline LILW-LL & $\mathrm{m}^{3} /$ TWhe & 1.4 & $21.0 \%$ \\
\hline HLW & $\mathrm{m}^{3} /$ TWhe & 0.30 & $-16.6 \%$ \\
\hline
\end{tabular}

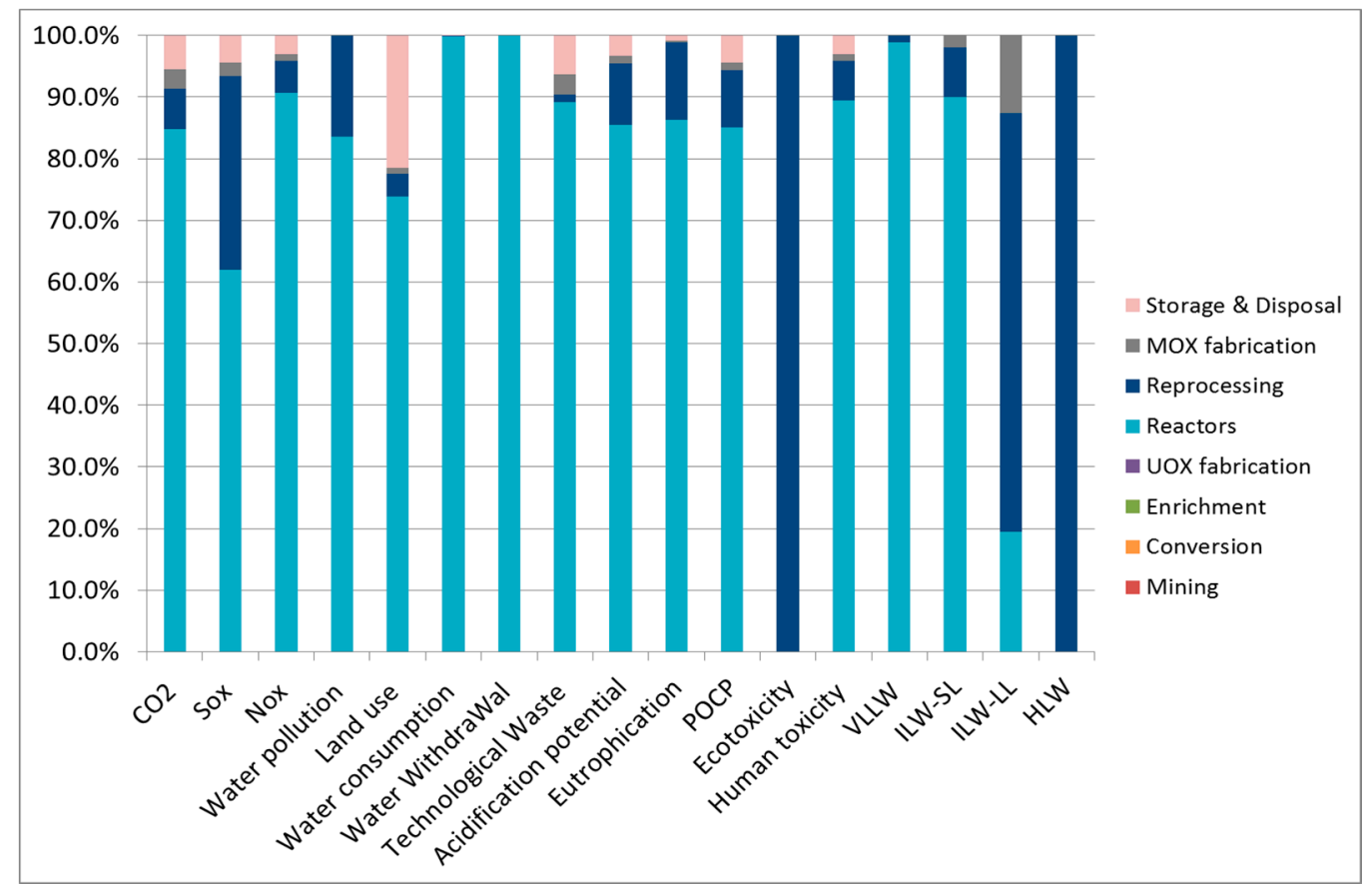

Figure 8. Relative contribution of each step of the fuel cycle to the environmental and technological impact indicators for the SFR scenario. 


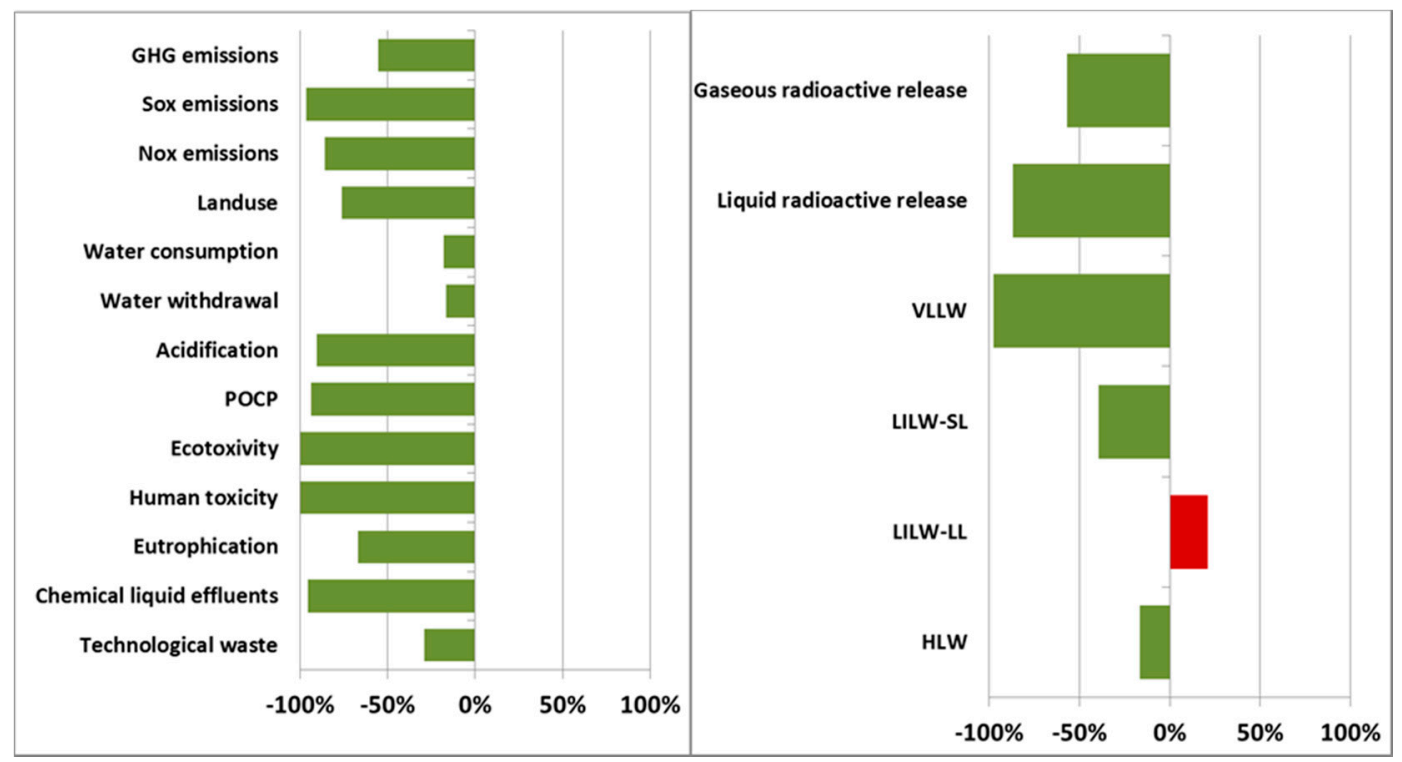

Figure 9. Comparison of the environmental indicators for the current French TTC [3] and the 100\% SFR case study.

Regarding the specific radioactive releases, the radioactive gaseous emissions represent nearly 99.3\% of the total radioactive emissions, which is very similar to the EPR case (almost 97\%) and the current French TTC (nearly 98\%). The absence of any mining operation in SFR removes the large contribution of radon leading to an important decrease in radioactive gaseous emissions against the current TTC $(-57 \%)$. As shown in Figure 10, the radioactive gaseous emissions are therefore mainly coming from rare gases emitted during the SNF dissolution in the reprocessing plant. The radioactive release at a potential SFR reprocessing plant is expected to be significantly different from the LWR reprocessing. Indeed, in LWR fuels, tritium produced remains mainly trapped in fuel pins thanks to Zircaloy cladding and is thus maintained in the liquid phase and released within the liquid radioactive release. For LWR reprocessing plant, tritium hence represents 80 to $90 \%$ of the total radioactive liquid release as shown before. The situation is quite different in SFR where $99 \%$ of tritium migrates from the fuel material to the sodium coolant through the steel cladding during the reactor operation as evidenced from the operation of the PHENIX reactor in Marcoule (France). Tritium transferred to the sodium coolant is further trapped as sodium hydrides by a range of traps (metallic frits, liquid nitrogen cooled activated charcoal traps ... ), limiting its release as gas at the reactor level and also strongly preventing its subsequent release during SFR fuel reprocessing [18]. As a conclusion, the total radioactive releases are expected to be significantly decreased in $100 \%$ SFR case study by comparison to the current French TTC ( $-98 \%)$.

For radioactive solid waste, a strong reduction $(-98 \%)$ is observed for VLLW due to the suppression of the mining operation. Improvements are also observed to a lesser degree for ILW-SL $(-40 \%)$ as for ILW-LL $(-21 \%)$ and HLW $(-17 \%)$, since they are dependent on reactors and reprocessing step.

\subsection{Environmental Indicators for a Case Study of the Am-Sole Recycling in FNR}

In addition to the sole Pu-multi-recycling in FNR detailed in the previous section, an additional case-study was considered in which Am is recovered in the reprocessing plant and is included in Am-bearing radial blankets to allow its transmutation in heterogeneous mode [31]. The nuclear material fluxes implemented in this scenario are given in Figure 11. Compared to SFR fuel cycle, this scenario requires an additional workshop for the separation of Am in the reprocessing plant and a fuel manufacturing plant able to produce Am bearing fuels. 


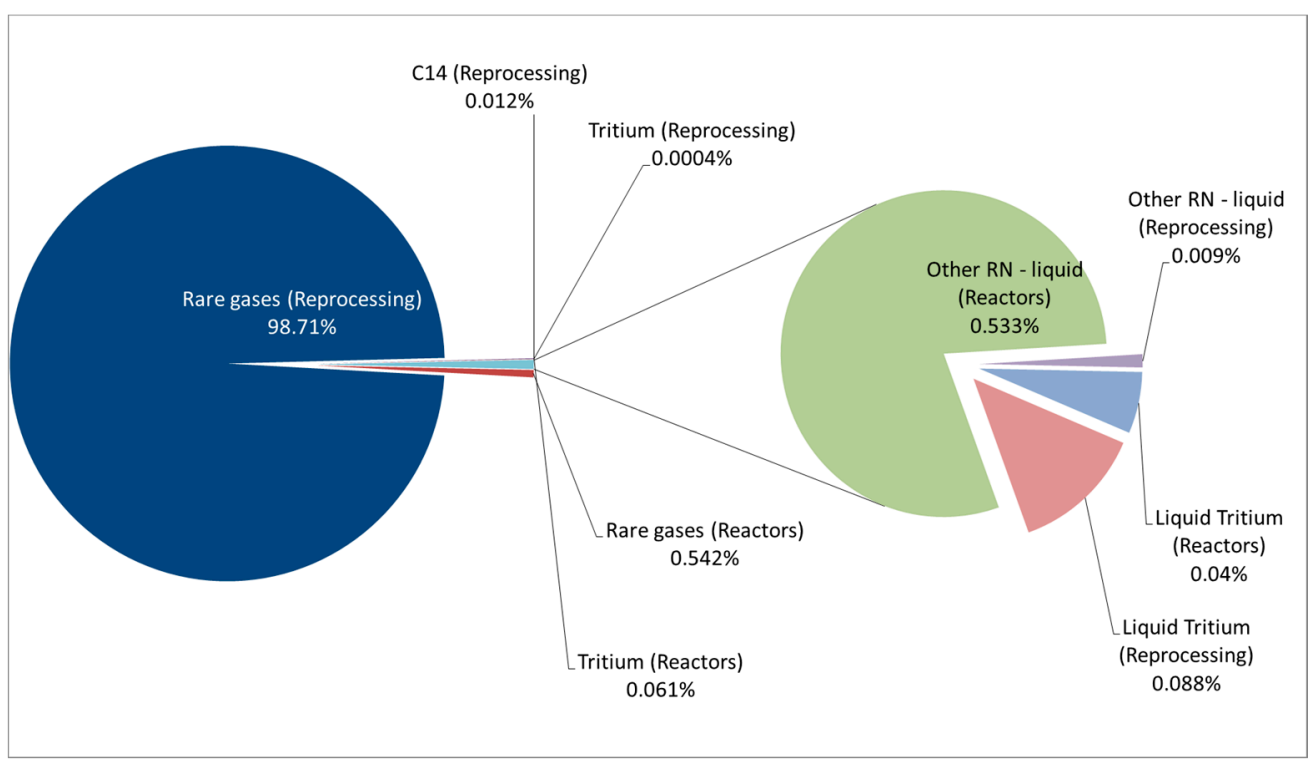

Figure 10. Main contribution associated to gaseous (528 kBq/kWhe) and liquid releases (3557 Bq/kWhe) for the $100 \%$ SFR case study.

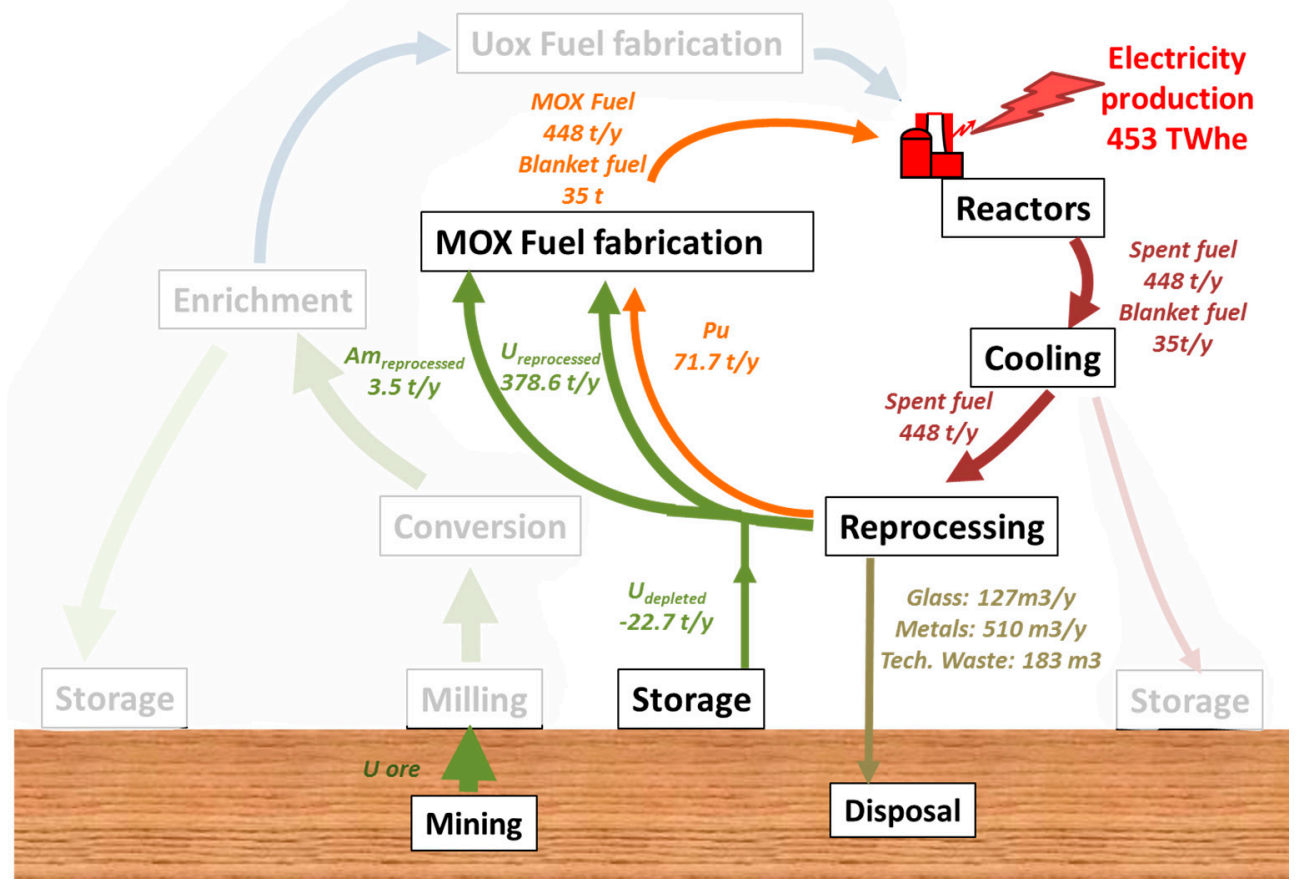

Figure 11. SFR fuel cycle including americium transmutation and its representative streams.

Globally, this new recycling scenario does not bring any noticeable changes vs. the previous $100 \%$ SFR case-study for most of the environmental impact indicators, the difference being $<10 \%$.

The only significant differences concern the radioactive waste, namely the VLLW, LILW-SL and LILW-LL which are respectively reduced by $27 \%, 8 \%$ and increased by $7 \%$. These differences are related to the implementation additional recycling plants to handle and manage the Am. Due to the specific radioactivity of Am, this plant needs to be operated remotely in shielded lines, and therefore produces additional LILW-LL. 


\section{Fuel Cycle Evolutions and Comparison}

This study allows the assessment of the environmental footprint of various types of potential future fuel cycles, from the $100 \%$ EPR case study which only differs from the current French TTC by the replacement of GEN II PWR reactors by GEN III EPR reactors, and the $100 \%$ SFR case study (+/- Am recycling) which requires a deeper modification with the implementation of Fast Neutron Reactors, the suppression of the front-end activities and the increase of the back-end activities (Table 4). Such an evolution from GEN II to GEN III, then GEN III to GEN IV reactors corresponds to the reference strategy in many nuclear countries such as France. It implies an increasing role of the back-end activities, and especially the recycling operations. It is therefore interesting to see what are the generic trends governing the evolution of the various environmental indicators. Figure 12 depicts the evolution of the various environmental indicators for these different types of reactors and fuel cycles.

Table 4. Comparison of the different environmental indicators for the $100 \%$ SFR and $100 \%$ $\mathrm{SFR}+$ Am-sole recycling case-studies.

\begin{tabular}{|c|c|c|c|c|}
\hline Impact Indicators & Unit & $100 \%$ SFR Case-Study & $\begin{array}{c}100 \% \text { SFR Case Study + Am-Sole } \\
\text { Recycling }\end{array}$ & Difference $\%$ \\
\hline GHG emissions & $\mathrm{gCO}_{2} \mathrm{eq} / \mathrm{kWhe}$ & 2.33 & 2.39 & $2.7 \%$ \\
\hline $\mathrm{SO}_{\mathrm{x}}$ emissions & g/MWhe & 0.59 & 0.61 & $2.9 \%$ \\
\hline Landuse & $\mathrm{m}^{2} / \mathrm{GWhe}$ & 50.2 & 50.4 & $0.4 \%$ \\
\hline Water consumption & L/MWhe & 1237 & 1237 & $0.0 \%$ \\
\hline Water withdrawal & L/MWhe & 60,336 & 60,337 & $0.0 \%$ \\
\hline Ecotoxivity & g1,4-DCB eq/MWhe & 0.071 & 0.077 & $7.8 \%$ \\
\hline Human toxicity & g1,4-DCB eq/MWhe & 4.8 & 4.8 & $0.8 \%$ \\
\hline Eutrophication & $\mathrm{gPO}_{4}$ eq/MWhe & 1.8 & 1.9 & $6.8 \%$ \\
\hline Liquid chemical effluents & $\mathrm{kg} / \mathrm{GWh}$ & 13 & 14 & $9.9 \%$ \\
\hline Technological waste & $\mathrm{kg} / \mathrm{GWhe}$ & 18.7 & 18.4 & $-1.8 \%$ \\
\hline Gaseous radioactive release & $\mathrm{kBq} / \mathrm{kWhe}$ & 528 & 568 & $7.8 \%$ \\
\hline HLW & $\mathrm{m}^{3} /$ TWhe & 0.30 & 0.28 & $-5.4 \%$ \\
\hline
\end{tabular}

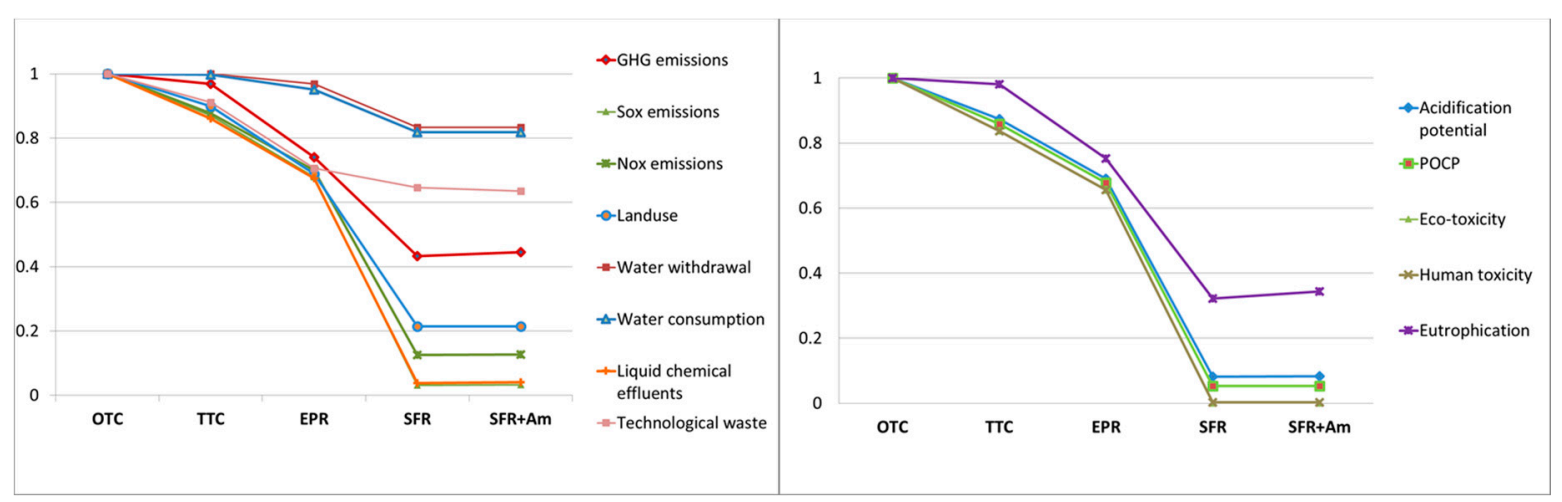

Figure 12. Evolution of the relative values of the various environmental indicators normalized to the OTC fuel cycle without any recycling. From the left to the right, the different fuel cycles implies increasing recycling activities.

It clearly demonstrates that implementing increasing recycling activities, from OTC to TTC, then to $100 \%$ SFR, then to $100 \%$ SFR + Am-recycling, yields to improving the environmental indicators. Recycling activities have therefore a very beneficial impact on the overall environmental footprint, since their impact are relatively low by comparison to the front-end activities. 
Finally, Figure 13 presents the anticipated evolution of the volumes of the different categories of waste which are supposed to be disposed of in the deep underground geological repository, and the respective repository surface and volume required. This figures shows that the implementation of the recycling does not significantly modify the total volume of waste, but strongly reduces the HLW which require most of the repository surface due to their high residual thermal power. It therefore leads to a significant decrease of the repository surface and volume with the increasing implementation of the recycling. These findings are important for two reasons:

- The repository surface is a given characteristic of a repository site, and it cannot a priori be easily extended. Reducing the surface needed for a given electricity production would allow operating such a repository for much longer time. Considering the complexity and time needed to find a suitable site and get it approved, it is a substantial gain.

- The repository volume corresponds to the volume of materials to be excavated, which influences directly the cost of construction of the repository. Reducing the repository volume means hence reducing the repository cost.

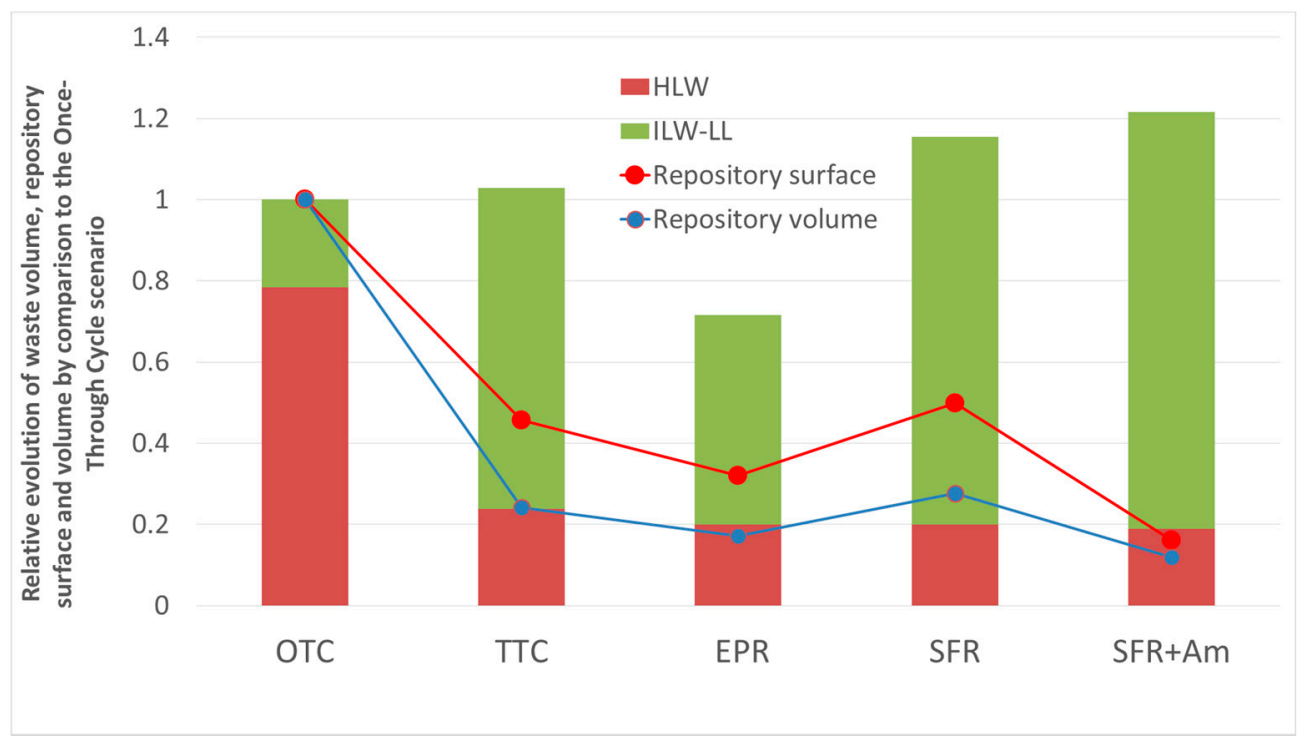

Figure 13. Evolution of the relative volume of High Level Waste (HLW), Long-Lived Intermediate Level Waste (ILW-LL), Repository surface and Repository volume between the various types of fuel cycles, normalized to the situation in the Once-Through Cycle (OTC).

\section{Conclusions}

By using NELCAS and a specific database describing different fuel cycle options based on GEN II, GEN III and GEN IV reactor systems, this study shows that the EPR already brings an improvement to the current fuel cycle (about 20\%) thanks to a higher efficiency of the energy transformation and a higher burn-up of the nuclear fuel whereas the introduction of the GEN IV fast reactors will bring a significant breakthrough by suppressing the current front-end of the fuel cycle (from 20 to $99 \%$ depending on the indicator). The specific case of the radioactive waste management is also studied, showing that only the partitioning and transmutation of the americium in the blanket fuel of the SFR can reduce the footprint of the geological disposal.

Having now at disposition five models (open fuel cycle, current French twice through fuel cycle, EPR twice through fuel cycle, multi-recycling SFR fuel cycle and at a longer term, multi-recycling SFR fuel cycle including americium transmutation), it is possible to model the environmental impact of any fuel cycle combining these technologies. In the next step, these models will be combined with those of other carbon-free energies (wind, solar, biomass ... ) in order to estimate the environmental 
impact of future energy mixes and also to analyze the impact on the way these scenarios are deployed (transition pathways).

The authors acknowledge that such a work is only one contribution to the debate on the energy transition, addressing specifically the different nuclear fuel cycle options and their environmental impacts under normal operation. It does not prevent a debate on the politics and economic issues and a debate on the nuclear accident risk and impacts. However, it delivers clear information on the advantages and drawbacks of one or the other options in future energy mixes, demonstrating the interest to keep nuclear energy in these carbon-free mixes together with renewable energies.

Acknowledgments: The authors would like to acknowledge Jean-François Milot, Anne Saturnin and Jean-Louis Girotto, Noël Ouvrier from CEA Research Department for Mining and Fuel Recycling Processes for fruitful discussions and information on construction, dismantling and transport as well as the CEA STECY project for its support.

Author Contributions: Implementation of fuel cycle data in NELCAS and the NELCAS calculations were performed by Jerôme Serp. The definition of the fuel cycle facility models and hypothesis as well as the selection of data were reviewed and validated by Stéphane Bourg. The whole strategic approach was defined by Christophe Poinssot.

Conflicts of Interest: The authors declare no conflict of interest.

\section{Abbreviations}

\begin{tabular}{|c|c|}
\hline COP21 & 21st Conference of Parties, December 2015, Paris \\
\hline LCA & Life Cycle Assessment \\
\hline NELCAS & Nuclear Energy Life Cycle Assessment Simulation tool, bespoke LCA CEA code \\
\hline SNF & Spent Nuclear Fuel \\
\hline OTC & Once-Through Cycle \\
\hline TTC & Twice-Through Cycle \\
\hline MTC & Multi-Through Cycle \\
\hline UOX & Uranium Oxide Fuel \\
\hline MOX & Mixed uranium/plutonium Oxide Fuel \\
\hline URE & Uranium re-enriched Fuel (nuclear fuel made from re-enriched-reprocessed uranium) \\
\hline BWR & Boiling Water Reactor \\
\hline LWR & Light Water Reactors \\
\hline PWR & Pressurized Water Reactor \\
\hline EPR & European Pressurized Reactor \\
\hline FNR & Fast Neutron Reactor \\
\hline SFR & Sodium cooled Fast Reactor \\
\hline P\&T & Partitioning and Transmutation \\
\hline $\mathrm{GWd} / \mathrm{tU}$ & GigaWatt Day per ton of uranium \\
\hline kWe, MWe, GWe, TWe & Kilo, Mega, Giga or Tera Watt electric \\
\hline $\begin{array}{l}\text { kWhe, MWhe, GWhe, } \\
\text { TWhe }\end{array}$ & Kilo, Mega, Giga or Tera Watt hour electric \\
\hline GB I & Georges Besse I (French enrichment plant based on gaseous diffusion) \\
\hline GB II & Georges Besse II (French enrichment plant based on ultra-centrifugation) \\
\hline SWU & Separative Work Units \\
\hline CESAR & Simplified Evolution Code Applied to Reprocessing developed by CEA \\
\hline COSI & Commelini-Sicard Code for Nuclear Fuel Cycle Simulation developed by CEA \\
\hline VLLW & Very-low-level waste \\
\hline LILW-SL & Low and Intermediate Level Waste, Short-Lived \\
\hline LILW-LL & Low and Intermediate Level Waste, Long-Lived \\
\hline HLW & High Level Waste \\
\hline POCP & Photochemical Ozone Creation Potential \\
\hline GHG & Green House Gases \\
\hline
\end{tabular}




\section{References}

1. International Organization for Standardization. ISO 14040: Environmental Management-Life Cycle Assessment_-Principles and Framework; International Organization for Standardization: Geneva, Switzerland, 2006.

2. International Organization for Standardization. ISO 14044: Environmental Management-Life Cycle Assessment-Requirements and Guidelines; International Organization for Standardization: Geneva, Switzerland, 2006.

3. Poinssot, C.; Bourg, S.; Ouvrier, N.; Rostaing, C.; Bruno, J. Assessment of the environmental footprint of nuclear energy systems. Comparison between closed and open fuel cycles. Energy 2014, 69, $199-211$. [CrossRef]

4. Kadiyala, A.; Kommalapati, R.; Huque, Z. Quantification of the Lifecycle Greenhouse Gas Emissions from Nuclear Power Generation Systems. Energies 2016, 9, 863. [CrossRef]

5. Cerullo, N.; Lomonaco, G. Generation IV reactor designs, operation and fuel cycle. In Nuclear Fuel Cycle Science and Engineering; Woodhead Publishing Limited: Cambridge, UK, 2012; Chapter 13.

6. GEN IV International Forum. Available online: https://www.gen-4.org/gif/jcms/c_9373/publications (accessed on 15 September 2017).

7. Chersola, D.; Lomonaco, G.; Marotta, R. The VHTR and GFR and their use in innovative symbiotic fuel cycles. Prog. Nucl. Energy 2015, 83, 443-459. [CrossRef]

8. Vezzoni, B.; Cerullo, N.; Forasassi, G.; Fridman, E.; Lomonaco, G.; Romanello, V.; Shwageraus, E. Preliminary Evaluation of a Nuclear Scenario Involving Innovative Gas Cooled Reactors. Sci. Technol. Nucl. Install. 2009, 2009, 1-16. [CrossRef]

9. Heuer, D.; Merle-Lucotte, E.; Allibert, M.; Brovchenko, M.; Ghetta, V.; Rubiolo, P. Towards the thorium fuel cycle with molten salt fast reactors. Ann. Nucl. Energy 2014, 64, 421-429. [CrossRef]

10. Agence Nationale Pour la Gestion des Déchets Radioactifs (ANDRA). Inventaire National des Matières et Déchets Radioactifs, Les Essentiels 2015; ANDRA: Châtenay-Malabry, France, 2015.

11. Yue, Q.; He, J.; Stamford, L.; Azapagic, A. Nuclear Power in China: An Analysis of the Current and Near-Future Uranium Flows. Energy Technol. 2017, 5, 681-691. [CrossRef]

12. Ritter, G.; Eschbach, R.; Girieud, R.; Soulard, M. CESAR5.3: Isotopic depletion for research and testing reactor decommissioning. In Proceedings of the European Research Reactor Conference (RRFM), Rotterdam, The Netherlands, 14-18 May 2017.

13. Coquelet-Pascal, C.; Tiphine, M.; Krivtchik, G.; Freynet, D.; Cany, C.; Eschbach, R.; Chabert, C. COSI6: A tool for nuclear transition scenario studies and application to sfr deployment scenarios with minor actinide transmutation. Nucl. Technol. 2015, 192, 91-110. [CrossRef]

14. Electricite De France (EDF). Flamanville 3-Tête de Série EPR-Dossier du Maître d'Ouvrage, 18/07/2005; EDF: Paris, France, 2005.

15. Quille Industrie, Centrale Electronucléaire de Flamanville-Fiche Terrassements et Génie Civil. Available online: www.infociments.fr/telecharger/CM-OA-2010.pdf (accessed on 19 September 2017).

16. Dones, R.; Bauer, C.; Bollinger, R.; Faist Emmenegger, M.; Frischknecht, R. Life Cycle Inventory of Energy Systems in Switzerland and Other UCTE Countries, Data V2.0; PSI: Villigen, Switherland; Ecoinvent Centre: Zurich, Switzerland, 2007.

17. Electricite De France (EDF). Dossier de Presse: Creys-Malville, Site Industriel, Territoire d'Avenir, Février 2011; EDF: Paris, France, 2011.

18. Guidez, J. Phénix: Le Retour D'expérience; EDP Sciences: Les Ulis, France, 2013.

19. Guidez, J.; Prêle, G. Superphenix: Les Acquis Techniques et Scientifiques; Atlantis Press: Amsterdam, The Netherlands, 2016.

20. AREVA. Document de Référence; AREVA: Paris, France, 2010.

21. AREVA. Rapport de Sûreté Nucléaire et Radioprotection du Site de La Hague; AREVA: Paris, France, 2010.

22. Agence Nationale Pour la Gestion des Déchets Radioactifs (ANDRA). Catalogue Descriptif des Familles de Déchets Radioactifs; ANDRA: Châtenay-Malabry, France, 2006.

23. AREVA. Données Chiffrées et Informations sur la Sûreté Nucléaire et la Radioprotection du Site AREVA Tricastin, 2008-2010; AREVA: Paris, France, 2010.

24. AREVA. Rapport D'information sur la Sûreté Nucléaire et la Radioprotection de MELOX; AREVA: Paris, France, 2010. 
25. Agence Nationale Pour la Gestion des Déchets Radioactifs (ANDRA). Inventaire National des Matières et des Déchets Radioactifs; ANDRA: Châtenay-Malabry, France, 2009.

26. Électricité de France (EDF). La Déconstruction de Superphénix du 28/09/2010; EDF: Paris, France, 2010.

27. Lecointe, C.; Lecarpentier, D.; Maupu, V.; Le Boulch, D.; Richard, R. Final Report on Technical Data, Costs and Life Cycle Inventories of Nuclear Power Plants (Report D14.2-RS 1a). 2007. Available online: http:/ / www. needs-project.org/2009/Deliverables/RS1a\%20D14.2\%20Final\%20report\%20on\%20nuclear.pdf (accessed on 19 September 2017).

28. Électricité de France (EDF). Dossier de Presse EDF, Le Projet EPR (European Pressurized Water Reactor) à Flamanville 3; EDF: Paris, France, 2007.

29. Électricité de France (EDF); AREVA. UK EPR GDA Project-Instruction, Reference Design Configuration, 06/12/2012; EDF; AREVA: Paris, France, 2012.

30. Électricité de France (EDF). Rapport annuel 2012 de Surveillance de l'Environnement-FLAMANVILLE; EDF: Paris, France, 2012.

31. Poinssot, C.; Gin, S. Long-term Behavior Science: The cornerstone approach for reliably assessing the long-term performance of nuclear waste. J. Nucl. Mater. 2012, 420, 182-192. [CrossRef]

(C) 2017 by the authors. Licensee MDPI, Basel, Switzerland. This article is an open access article distributed under the terms and conditions of the Creative Commons Attribution (CC BY) license (http:/ / creativecommons.org/licenses/by/4.0/). 